\title{
Wavelet Based Power Quality Assessment of Wind Energy Source Integrated 5-Bus System under Sudden Load Conditions in Presence of FACTS Devices
}

\author{
J. Pardha Saradhi, R. Srinivasa Rao, V.Ganesh
}

\begin{abstract}
The structure, operation, and planning of electric power networks will undergo considerable and rapid changes due to increased global energy consumption. The requirement of renewable energy sources due to the increase of electrical demand. This paper presents wind energy integration with electrical grid under impact on sudden load conditions. To fill the demand and supply gap requires reactive power. To compensate reactive power more prominent devices are needed. The Static Synchronous Series Compensator (SSSC), Static Synchronous Compensator (STATCOM) and Unified power flow controller (UPFC) are the members of the Flexible AC Transmission system family having very attractive features of series and shunt reactive power compensating devices. The proposed research work is carried by wavelet multi resolution analysis using Bior1.5 mother wavelet under Power Quality issue of sudden load 150MW is introduced at bus-3, which can be compensated by a wind energy source and FACTS devices. The analysis of 5-bus network model of sudden load impact is tested and observed that the effectiveness of the system with Wind Energy source integration in presence of SSSC, STATCOM \&UPFC.
\end{abstract}

Keywords : wind farm; sudden load; wind energy sourc; SSSC; STATCOM;UPFC.

\section{INTRODUCTION}

Electric utility companies are searching to install wind turbines as one of the energy source to meet the customer load demand. The problem remains in existing power systems which is discussed in $[1,2]$. The installation of wind energy stations in electrical networks has provided many benefits such as improving the environment, reliability, reducing, voltage instability[1,2] and stabilizing energy prices $[3,4]$. The improper allocation of wind farms may increase the losses in the power system network [5].Wind power plants will provide a better alternative for compensate the power deficit of electrical grids as compared with large scale hydro and thermal units.

Flexible AC Transmission Systems (FACTS) based power electronic converters like the unified power flow controller (UPFC) is extensively used in power Systems because of their ability to provide series as well as shunt power flow control[6,7]. The SSSC is a series converter which controls

Revised Manuscript Received on September 22, 2019

* Correspondence Author

J .Pardha Saradhi, ${ }^{a}$ Bapatla Engineering College,Bapatla 523155,India

R.SrinivasaRao, JNTU,Kakinada 533001, India

V.Ganesh, JNTUA,Pulivendula 516390,India the line active and reactive power flow by injecting a series voltage of adjustable magnitude and phase angle.

The wind energy integration with existing power system on voltage stability by using the Flexible AC Transmission System (FACTS) has been presented. Wavelet Theory is the mathematics for analyzing periodic and non periodic signals, with a set of components that are small waves of short duration discussed in. Electric power quality can be defined as a measurement of electric power service can be utilized by loads. At the time of dynamic load conditions the voltage, current signal are irregular. A wavelet analysis is one of the most considerable method to describe not only localize the disturbance but also provides the duration of the disturbance. The proposed research work is carried by wavelet multi resolution analysis using Bior1.5 mother wavelet under various Power Quality issues are described to calibrate performance analysis of 5-bus network model of sudden load impact is tested and observed that the effectiveness of the system with Wind Energy source integration in presence of UPFC.

\section{1wind Power Integration}

In the mostly dominated renewable energy sources are solar and wind energy. The process of bringing potential wind sites into synchronous operation with existing power grids is called wind power integration. The integration of wind power with existing electrical grid is shown in Fig. 1.

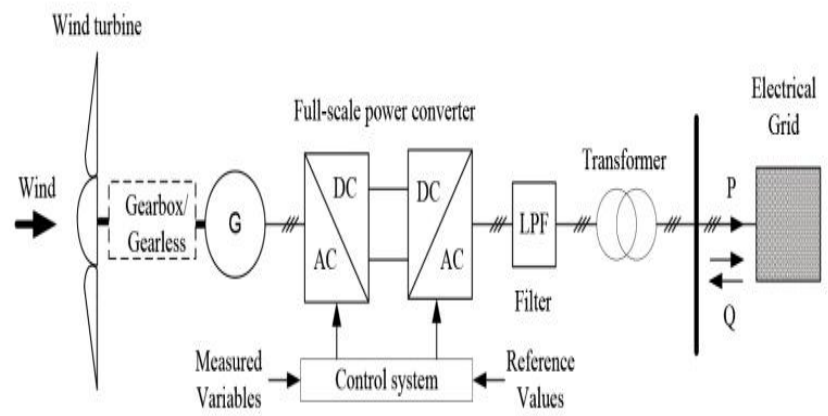

Figure 1: Wind turbine integration in an existing electrical grid.

The modern wind turbines have the reactive power capability and it consisting of Doubly Fed Induction Generator (DFIG) units. At present power electronic controls can provide fast acting dynamic reactive 
resource when compared to direct grid connected synchronous generators used in conventional power plants. The integration of the alternative energy production systems into existing power systems leads to the power quality problem.

\subsection{Wavelet Analysis}

Here wavelet analysis is applied and digital simulation is made based on multi resolution analysis for the entire system. Bior 1.5 is chosen for analysis, wavelet coefficients are taken. All the signals obtained during sudden load condition are decomposed using Bior1.5 wavelet and the detailed coefficients are used for further analysis.

\subsection{Power System Network Simulation Model}

The proposed 5-bus system with wind integration using MATLAB software taken for study is shown in Fig.3. The proposed model consists of $230 \mathrm{KV}, 150 \mathrm{MW}$ generator at bus-1, two $100 \mathrm{MW}$ wind sources at bus-4 and three loads of $60 \mathrm{MW}, 30 \mathrm{MW} \& 70 \mathrm{MW}$ at Bus-2, Bus-3\& Bus-5 are connected \& a sudden load of $150 \mathrm{MW}$ is connected at Bus3.The basic form of reactive power compensation using SSSC\&STATCOM and over loading by wind generation source. The FACTS devices has been placed in between buses 3 and 4 to serve the system under transient conditions which are produced due to sudden load kept on at BUS-3 and performance analysis has been carried under the following specifications are represented in Figure 3. The performance of system is evaluated without wind energy sources, and by considering the wind energy sources.

The network details are:

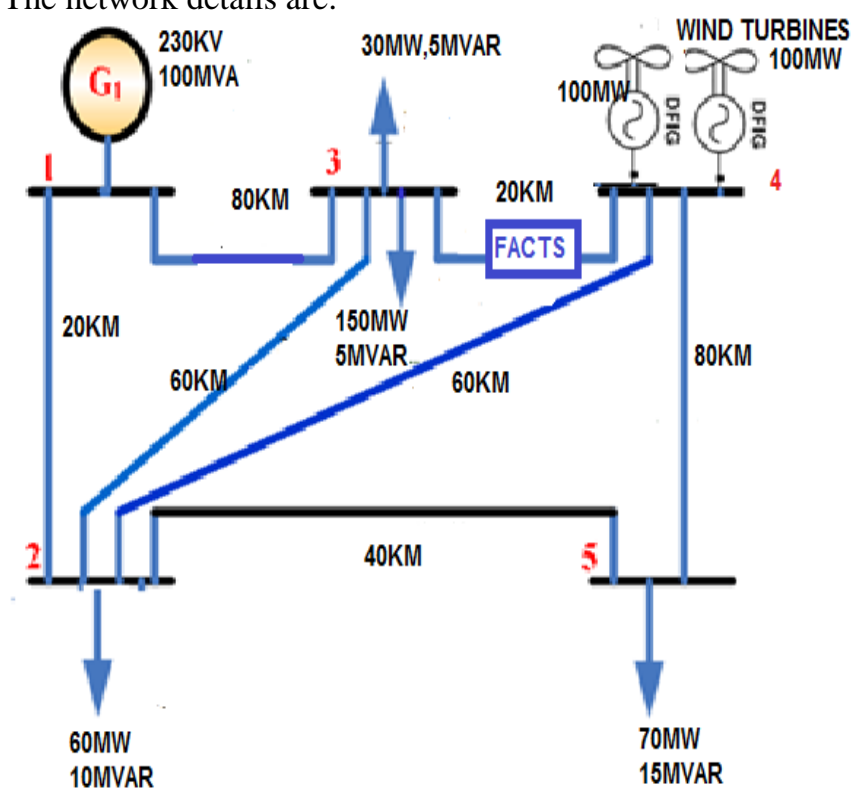

Figure.2: Representation of a 5-Bus system with wind integration.

\subsection{Result Analysis}

Performance analysis is carried under Sudden load is connected at Bus-3 and Wind energy sources are connected at
Bus4 with FACTS controllers are connected between buses 3 and 4.

The analysis of wavelet detailed coefficients of current signals under a normal load of $30 \mathrm{MW}$ is connected and a sudden load of $150 \mathrm{MW}$ is connected at the at Bus-3 is illustrated from figure 4 to Figure 12.It is observed that more impact on the terminal-2, Terminal-3 and Terminal-5, but there is no considerable effect on the terminal 1 and 4 due to respective buses are generation buses.

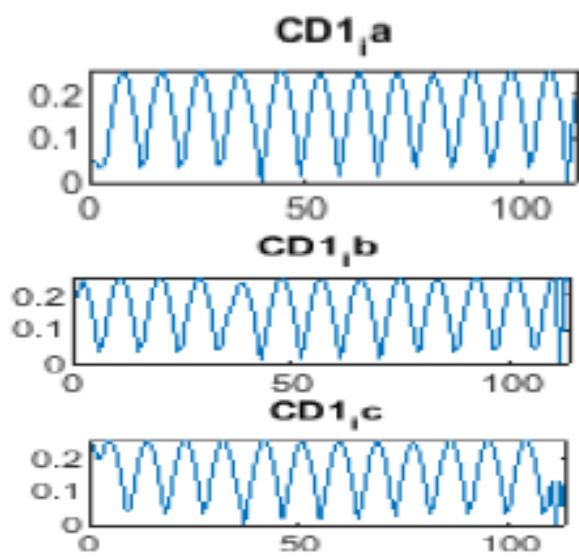

Figure 3: Detailed coefficients of current signal at bus-1 without connecting a wind energy source

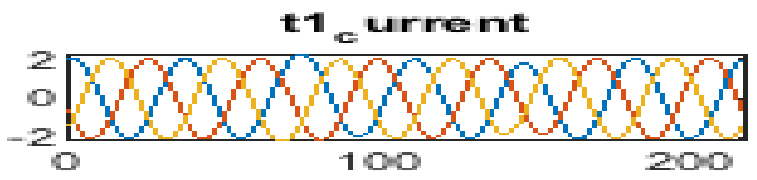

Figure 4: Three phase variation of current signal at bus-1 without connecting a wind energy source

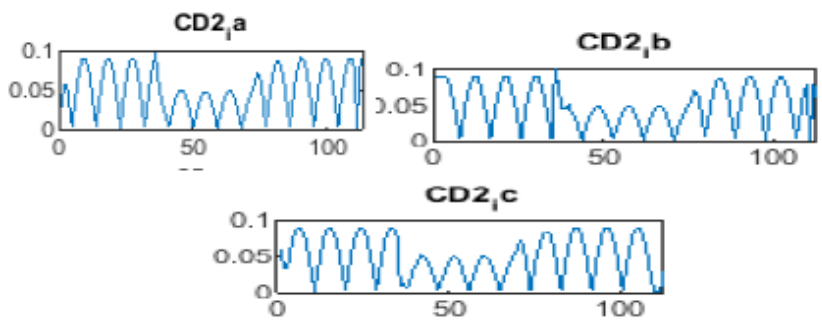

Figure 5: Detailed coefficients of current signal connected at bus- 2 without connecting a wind energy source

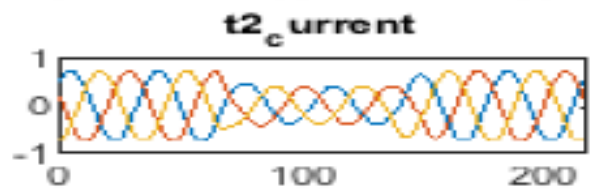

Figure 6: Three phase variation of current signal at terminal-2 without connecting a wind energy source 


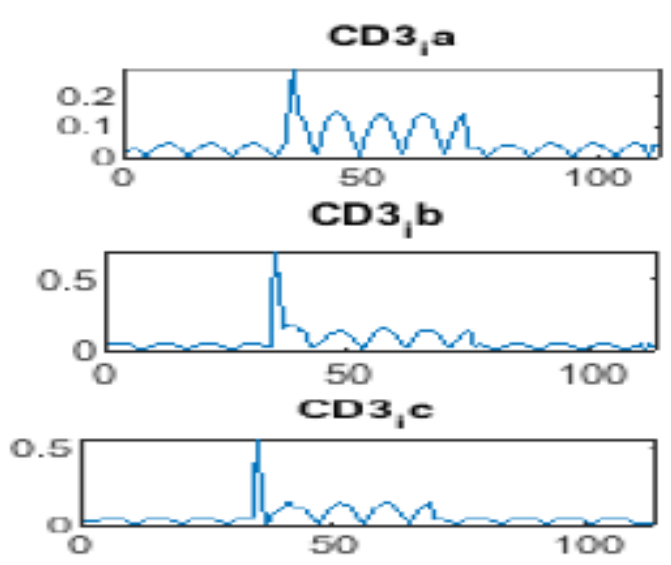

Figure 7: Detailed coefficients of current signal connected at bus-3 without connecting a wind energy source

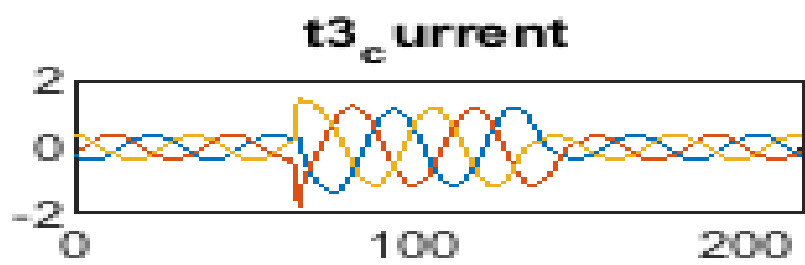

Figure 8: Three phase variation of current signal at terminal-3 under sudden load at bus-3 without connecting a wind energy source.

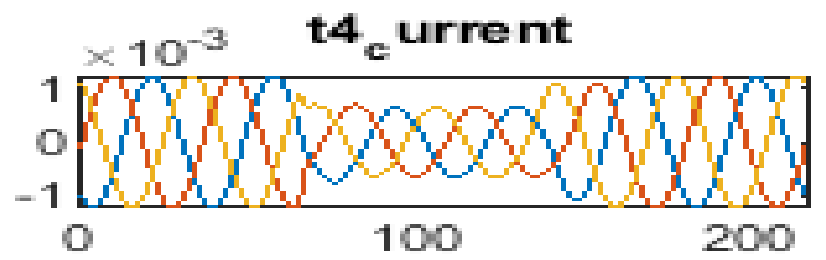

Figure 9: Three phase variation of current signal at terminal-4 under sudden load at bus-3 without connecting a wind energy source.

Figure 3 to Figure11 represent detailed coefficients at terminals $1,2,3,4 \& 5$. When sudden load of $150 \mathrm{MW}$ is connected at bus-3. Since Bus-1 is a generator bus hence not affected. Transient current will flow at bus 3 and considerable generator is unable to meet the requirements during sudden load conditions.

It is very much required to connect wind power plants to meet sudden transient load. To compensate the system parameters a $2-$ DFIGs of rated $100 \mathrm{MW}$ at are connected at bus4 in this work.Figure12 to Figure-15 represent the waveforms with wind energy sources are in operation to meet the sudden load on Bus-3.

Two DFIGs are able to control the transients caused due to sudden load connected at bus-3 up to reasonable value.

Moreover the transients in the lines as well as at terminals are well controlled by connecting FACTS controllers. The results being verified by using different FACTS controllers UPFC, SSSC\&STATCOM.

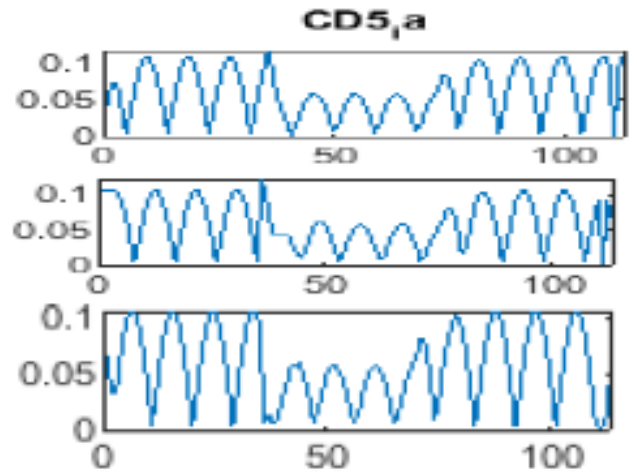

Figure 10: Detailed coefficients of current signal at bus-5Withoutconnecting a wind energy source

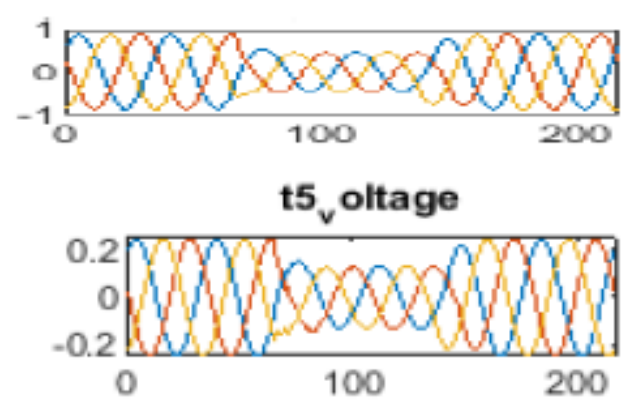

Figure 11: Three phase variation of current \&voltage signal at terminal-5 under sudden load at bus- 3 without wind energy source.
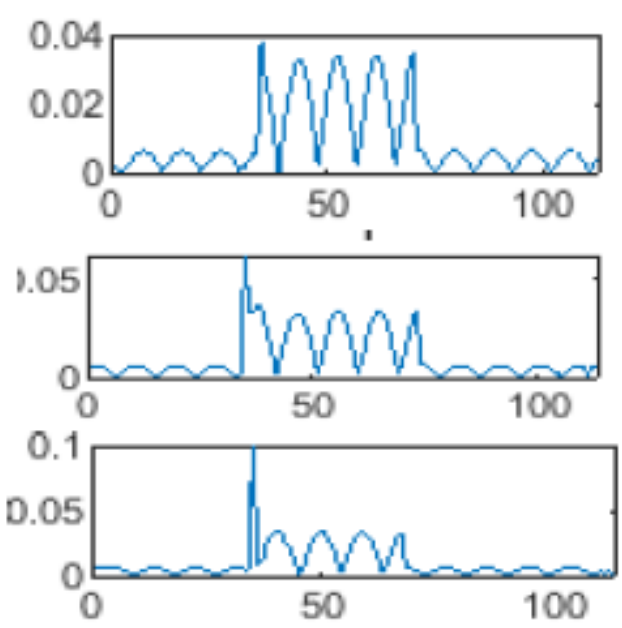

Figure 12: Current signal at terminal-3 under sudden load at bus-3 with wind energy source.

\section{t 3 current}

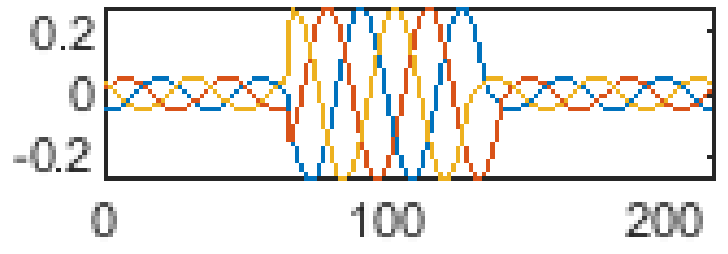

Figure 13: Three phase variation of current signal at terminal-3 under sudden load at bus-3 with wind energy

Source. 


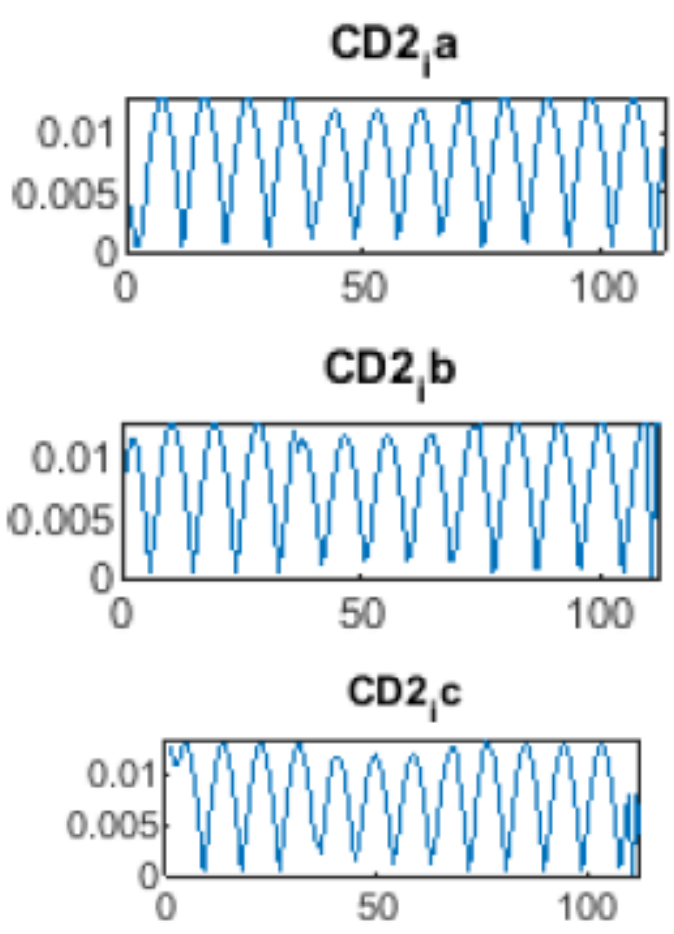

Figure 14: Current signal at terminal-2under sudden load at bus-3 with wind energy source.

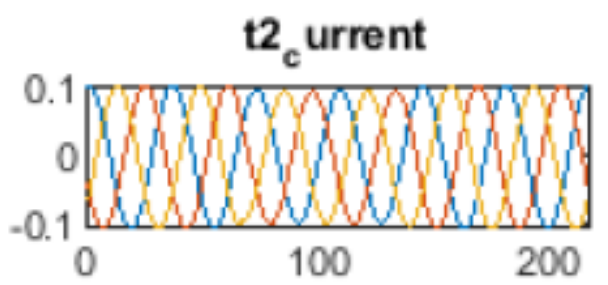

Figure 15: Three phase variation of current signal at terminal-2 under sudden load at bus-3 with wind energy source.

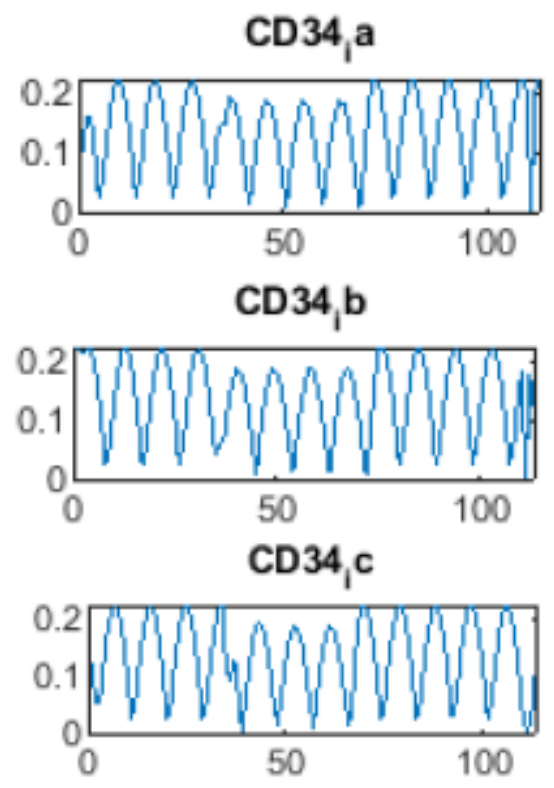

Figure 16: Variation of detailed coefficients of line-34 current signal between bus $3 \& 4$ under additional load connected at bus-3 with wind energy source.

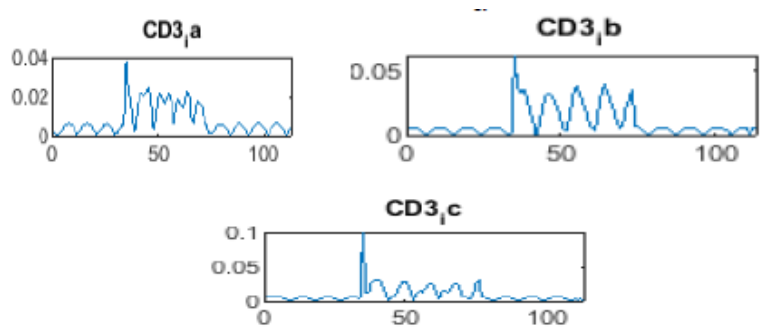

Figure 16: Current signal at terminal-3 under sudden load at bus- 3 with wind energy source and STATCOM

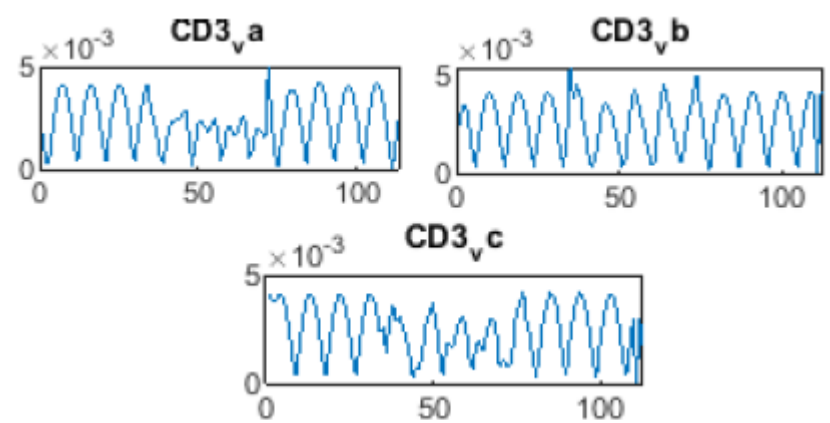

Figure 17: Voltage signal at terminal-3 under sudden load at bus-3 with wind energy source and STATCOM

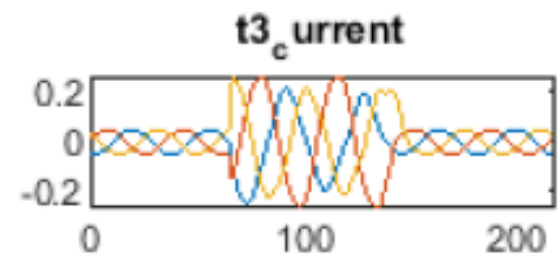

Figure 18: Three phase variation of Current signal at terminal-3 under sudden load at bus-3 with wind energy source and STATCOM

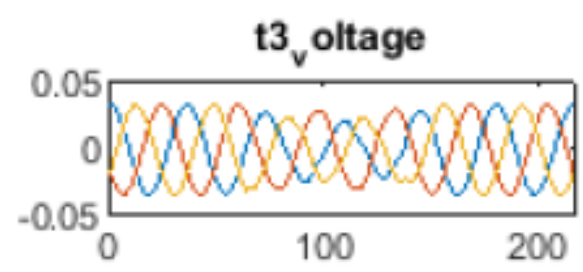

Figure 19: Three phase variation of Voltage signal at terminal-3 under sudden load at bus-3 with wind energy source and STATCOM

Figure-16 to Figure-20 represents the compensation of transient currents by using STATCOM analysed by using Wavelets at Bus-2, 3, 4\&5.

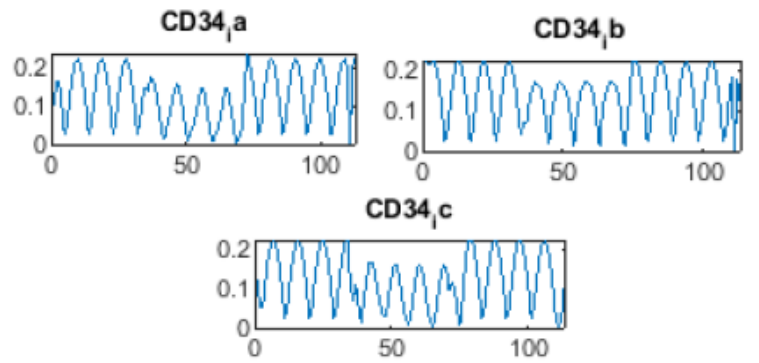

Figure 20: Variation of detailed coefficients of line-34 current signal between bus $3 \& 4$ under additional load connected at bus-3 with wind energy source and STATCOM 


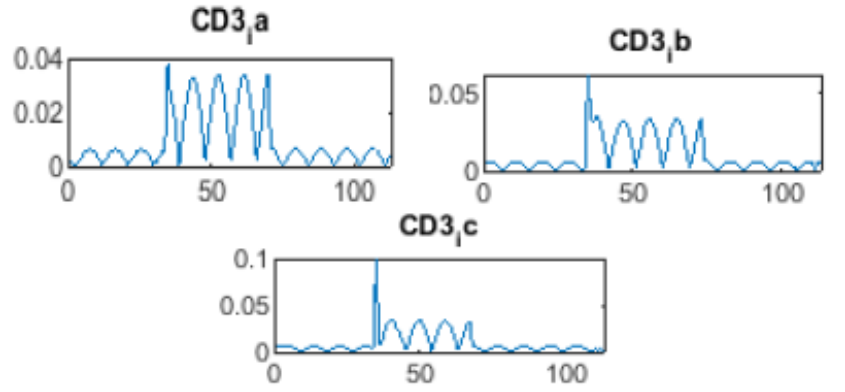

Figure 21: Current signal at terminal-3 under sudden load at bus-3 with wind energy source and SSSC

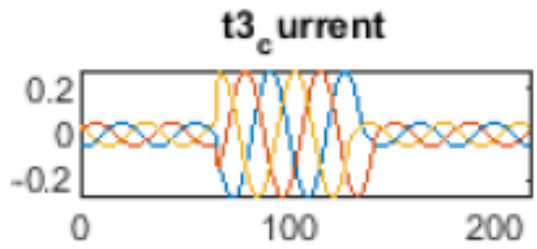

Figure 22: Three phase variation of Current signal at terminal-3 under sudden load at bus-3 with wind energy source and SSSC.

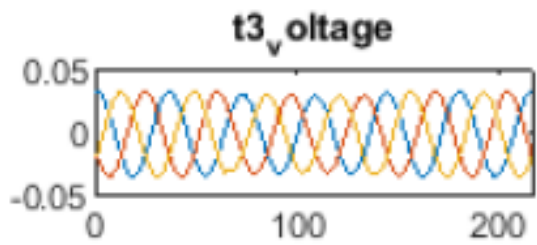

Figure 23: Three phase variation of Voltage signal at terminal-3 under sudden load at bus-3 with wind energy source and SSSC.

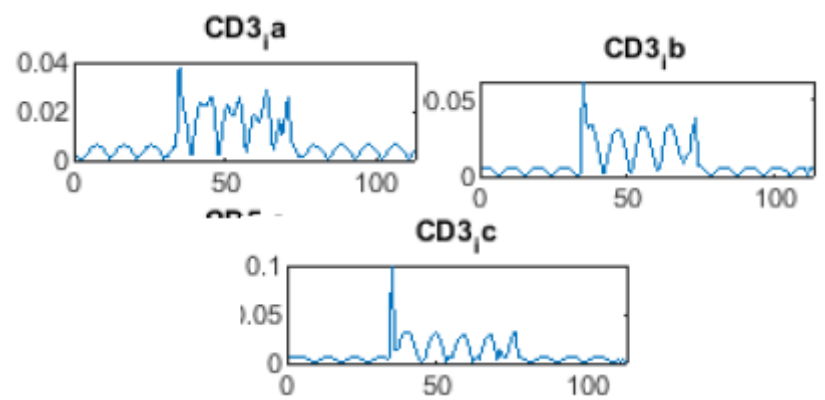

Figure 24: Current signal at terminal-3 under sudden load at bus-3 with wind energy source and UPFC.

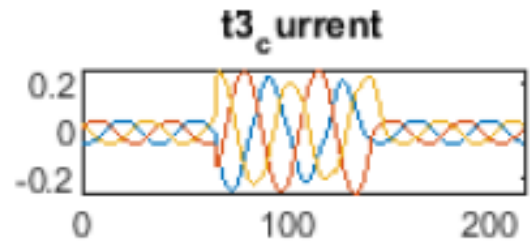

Figure 25: Three phase variation of Current signal at terminal-3 under sudden load at bus-3 with wind energy source With UPFC.

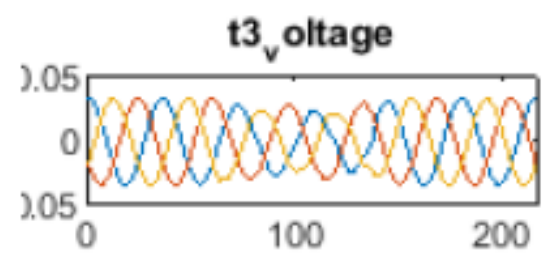

Figure 26: Three phase variation of Voltage signal at terminal-3 under sudden load at bus-3 with wind energy source With UPFC.

This paper mainly focused on compensation of the system under sudden load conditions, the analysis is made at all the buses and lines. From the results it can be concluded that SSSC given a good support to voltage\& STATCOM works on transient currents well. Whereas UPFC serves both the functions up to a better limit.

\section{CONCLUSION}

The major problems of inter connected networks had fluctuations in reliability of power supply and load fluctuations from time to time, which may lead to instability, difficult to control the power flow. Power quality problems can be minimized by inventing new techniques as per the requirement. Flexible AC Transmission system devices are more prominent devices to compensate reactive power and power quality problem mitigation. This paper presents the complete digital simulation of SSSC, STATCOM, and UPFC Compensated IEEE 5-Bus system with wind generation under sudden load conditions. The proposed model analysis compared with and without wind source behaviour of the system with shunt and series compensating devices. The performance is studied using wavelet multi resolution analysis with Bior1.5 mother wavelet. The proposed research work provide the micro analysis of inter connected multi bus system under load conditions with wind generation. The effectiveness of different FACTS devices has been evaluated.

\section{REFERENCES}

1. Karunya, 1., P.Harini, ., S.Iswarya, . \& A.Jerlin, . (2019) emergency alert security system for humans. International journal of communication and computer technologies, 7 (supplement 1), 6-10. Doi:10.31838/ijccts/07.sp01.02

2. T. Van Cutsem and C. Vournas, Voltage Stability of Electric Power Systems. Norwell, MA: Kluwer, 1998.

3. Masters, G.M. Renewable and Efficient Electric Power Systems; John Wiley \& Sons, Inc.: Hoboken, NJ, USA,2004.

4. Ackermann, T. Wind Power in Power Systems; John Wiley \& Sons, Ltd.: Chichester, UK, 2005.

5. Rao, B. Venkateswara, et al. "Optimal power flow by Newton method for reduction of operating cost with SVC models." 2009 International Conference on Advances in Computing, Control, and Telecommunication Technologies. IEEE, 2009.

6. N. G. Hingorani, "High Power Electronics and Flexible AC Transmission System” IEEE Power Eng., pp. 3-4, Jul 1998.

7. Lahaçania, N.A.; Aouzellaga, D.; Mendilb, B. Static compensator for maintaining voltage stability of wind farm integration to a distribution network. Renew. Energy 2010, 35, 2476-2482. 